\title{
MENENTUKAN RUJUKAN RUMAH SAKIT TERBAIK BAGI PASIEN BPJS MENGGUNAKAN METODE WEIGHTED SUM MODEL (WSM) PADA PUSKESMAS
}

\author{
Maulida Purba ${ }^{1}$, Marsono Marsono ${ }^{2}$, Rina Mahyuni ${ }^{3}$ \\ Program Studi Sistem Informasi, STMIK Triguna Dharma \\ Jl. Jenderal A. H. Nasution No.73, Kwala Bekala, Medan Johor, Kota Medan, Sumatera Utara 20146 \\ maulidapurba280796@gmail.com,marsonotgd@yahoo.com, rinamahyunitgd@gmail.com
}

\begin{abstract}
BPJS Health is one of the most important services for the community. For people who are sick and have been registered in BPJS, then the cost of treatment will be borne by the BPJS and the community is what is said as Patient BPJS. However, if a patient BPJS experiencing pain, then the patient first went to the health center or Faskes level 1 before being referred to the Hospital. Therefore, this study aims to build decision support system that has the ability to analyze in determining referral hospital for Patient BPJS at puskesmas or Faskes level 1. The method used in this research is Weighted Sum Model (WSM). The hospital samples used as many as 10 obtained from UPT Puskesmas Padang Bulan, Jln. Jamin Ginting - Medan. Based on calculations performed obtained the highest value of 77.5, ie on RS3. Therefore, this hospital is the foremost hospital as a reference for Patients BPJS. This research is expected to help the Puskesmas or Faskes level I in the city of Medan in providing hospital referrals for patients BPJS.
\end{abstract}

Keywords: Patients BPJS, Referral, Hospital, SPK, WSM, Puskesmas

\begin{abstract}
Abstrak
BPJS Kesehatan merupakan salah satu layanan yang sangat penting bagi masyarakat. Bagi masyarakat yang mengalami sakit dan telah terdaftar di BPJS, maka biaya pengobatannya akan ditanggung oleh pihak BPJS dan masyarakat tersebut lah yang dikatakan sebagai Pasien BPJS. Akan tetapi apabila seorang pasien BPJS mengalami sakit, maka pasien terlebih dahulu berobat ke puskesmas atau Faskes tingkat 1 sebelum dirujuk ke Rumah Sakit. Oleh karena itu Penelitian ini bertujuan untuk membangun sistem pendukung keputusan yang mempunyai kemampuan menganalisa dalam menentukan rumah sakit rujukan bagi Pasien BPJS pada puskesmas atau Faskes tingkat 1. Metode yang digunakan dalam penelitian ini yaitu Weighted Sum Model (WSM). Adapun sampel Rumah Sakit yang digunakan sebanyak 10 yang diperoleh dari UPT Puskesmas Padang Bulan, Jln. Jamin Ginting - Medan. Berdasarkan perhitungan yang dilakukan diperoleh nilai tertinggi sebesar 77,5, yakni pada RS3. Oleh karena itu, rumah sakit ini merupakan rumah sakit terdepan sebagai rujukan bagi Pasien BPJS. Penelitian ini diharapkan dapat membantu pihak Puskesmas atau Faskes tingkat I di kota Medan dalam memberikan rujukan rumah sakit bagi pasien BPJS.
\end{abstract}

Kata Kunci : Pasien BPJS, Rujukan, Rumah Sakit, SPK, WSM, Puskesmas

\section{PENDAHULUAN}

BPJS Kesehatan merupakan salah satu layanan penting untuk masyarakat. BPJS Kesehatan adalah badan hukum yang dibentuk untuk menyelenggarakan program jaminan kesehatan [1]. Oleh karena itu bagi masyarakat yang mengalami sakit dan telah terdaftar di BPJS, maka biaya pengobatannya akan ditanggung oleh pihak BPJS dan masyarakat tersebut lah yang dikatakan sebagai Pasien BPJS. Bagi pasien yang mengidap penyakit, baik ringan maupun berat harus tetap berobat terlebih dahulu dari tim medis Fasilitas Kesehatan tingkat I di Pusat Kesehatan Masyarakat (Puskesmas) atau klinik kesehatan yang dekat dengan tempat 
tinggalnya, sebelum berobat ke rumah sakit. Kemudian, jika fasilitas kesehatan tersebut tidak sanggup, maka akan dirujuk ke fasilitas kesehatan yang lebih tinggi atau Rumah Sakit. Dalam merujuk rumah sakit bagi pasien BPJS, puskesmas tidak lah sembarangan. Puskesmas harus tau Rumah sakit mana yang boleh dirujuk oleh pasien BPJS. Rumah Sakit rujukan adalah rumah sakit yang telah bekerjasama dengan BPJS. Jadi, tidak semua rumah sakit melayani pasien BPJS. Pada umumnya di rumah sakit yang sudah melakukan kerja sama dengan BPJS, loket untuk jaminan BPJS sudah disediakan di rumah sakit tersebut, dan biasanya lokasinya terpisah dengan loket registrasi. Pasien BPJS berhak meminta pergantian dari rumah sakit $\mathrm{A}$ ke rumah sakit $\mathrm{B}$ apabila rumah sakit $\mathrm{A}$ dianggap pelayanannya tidak baik atau tidak memiliki fasilitas yang lengkap untuk jenis penyakit yang diderita pasien [2][3].

Oleh karena itu diperlukan suatu analisis sistem [4][5]-[8], untuk menentukan rujukan Rumah Sakit. Salah satunya adalah dengan menggunakan Sistem Pendukung Keputusan. Karena Sistem Pendukung Keputusan (Deccision Support System) merupakan sebuah sistem yang mampu memberikan kemampuan pemecahan masalah maupun kemampuan pengkomunikasian yang dimanfaatkan untuk membantu manusia mengambil keputusan dengan cepat, tepat dan konsisten [9][10][11]. Salah satu Sistem Pendukung Keputusan yang dapat digunakan untuk menentukan Rujukan Rumah sakit bagi pasien BPJS pada Puskesmas adalah dengan menggunakan Metode WSM (Weighted Sum Model).

\section{METODE PENELITIAN}

\subsection{Pasien BPJS}

Pasien BPJS merupakan masyarakat Indonesia yang menjadi peserta jaminan kesehatan yang dikelola oleh BPJS termasuk orang asing yang telah bekerja paling singkat enam bulan di Indonesia dan telah membayar iuran [12].

\subsection{Rujukan Rumah Sakit}

Rumah sakit rujukan adalah rumah sakit yang telah bekerjasama dengan BPJS yang dianggap memiliki kinerja, mutu, pelayanan maupun fasilitas yang cukup baik [13].

\subsection{Sistem Pendukung Keputusan}

Sistem pendukung keputusan atau decision support sistem (DSS) adalah sistem informasi interakif yang menyediakan informasi, pemodelan, dan pemanipulasian data [14][15], [16]. Sistem Pendukung Keputusan (SPK) merupakan salah satu cara mengorganisir informasi yang dimaksudkan untuk digunakan dalam membuat keputusan [17].

\subsection{Weighted Sum Model (WSM)}

Metode Weighted Sum Model merupakan metode yang sangat umum, dan banyak diterapkan untuk membantu pengambil keputusan dalam mengambil suatu keputusan [18]. WSM merupakan salah satu metode yang sederhana dan mudah dipahami penerapannya. Merupakan bagian dalam metode MCDM(Multi Criteria Decison Making) dalam mengevaluasi nilai pada setiap alternatif.

$$
A_{i}{ }^{W S M-s c o r e}=\sum_{j=1}^{n} w_{j} x_{i j} \quad, \text { for }_{i}=1,2,3
$$


Dimana :

$\mathrm{n} \quad=$ Jumlah Kriteria

$\mathrm{W}_{\mathrm{j}} \quad=$ Bobot dari setiap kriteria

$\mathrm{X}_{\mathrm{ij}} \quad=$ Nilai matrik $x$

Nilai $A_{i}$ yang paling besar merupakan alternatif yang terpilih

Kesulitan pada metode ini adalah ketika yang digunakan bukanlah kriteria dimensi tunggal atau multi dimensi. Dalam permasalahan tersebut, maka kriteria yang ada harus disamakan menjadi satu dimensi yang sama [19].

\subsection{Flowchart Sistem}

Adapun flowchart sistem dalam tulisan ini dapat dilihat pada gambar 1 berikut.

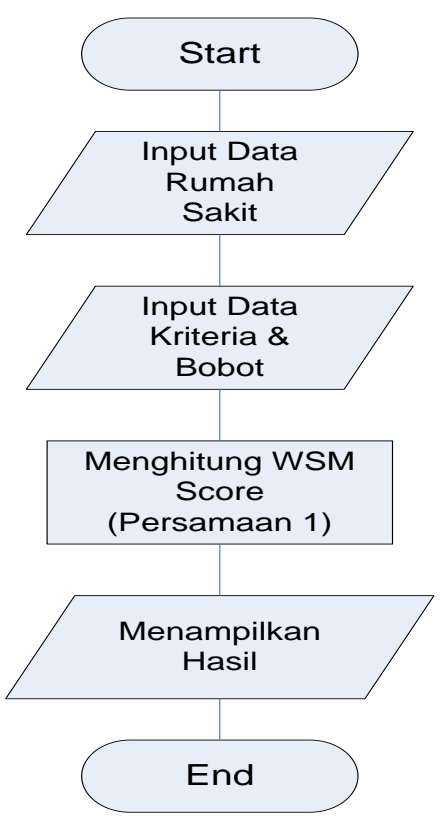

Gambar 1. Flowchart Sistem

Berdasarkan gambar 1 dapat dijelaskan bahwa alur atau langkah yang pertama dilakukan adalah menginput data rumah sakit, kemudian dilanjutkan dengan menentukan dan memasukkan data kriteria dan bobot. Data-data yang telah dimasukkan kedalam sistem kemudian akan di proses dan dihitung dengan menggunakan metode Weighted Sum Model (WSM). Setelah itu sistem akan menampilkan hasil perangkingan mulai dari yang terbaik sampai yang terendah berdasarkan data-data yang telah dimasukkan kedalam sistem.

\subsection{Data Yang Digunakan}

Data yang digunakan untuk penelitian ini adalah data-data yang diambil dari UPT Puskesmas Padang Bulan, Jln. Jamin Ginting - Medan. 


\subsection{Menentukan Kriteria Dan Bobot}

Adapun bobot dan kriteria yang dibutuhkan dalam penentuan rujukan rumah sakit terbaik bagi pasien pengguna BPJS dapat dilihat pada tabel 1 berikut.

Tabel 1. Normalisasi Data Training Tahun 2005-2009 / Target Tahun 2010

\begin{tabular}{|c|c|c|}
\hline Kode & Kriteria & Nilai Bobot(Wj) \\
\hline $\mathrm{C} 1$ & Gedung & 0.15 \\
\hline $\mathrm{C} 2$ & Fasilitas Rujukan & 0.15 \\
\hline C3 & Ketersediaan Dokter & 0.5 \\
\hline $\mathrm{C} 4$ & Pelayanan & 0.10 \\
\hline $\mathrm{C} 5$ & Kenyamanan & 0.10 \\
\hline \multicolumn{2}{|r|}{ Total } & 1 \\
\hline
\end{tabular}

Berdasarkan tabel 1 dapat dijelaskan bahwa Ketersediaan dokter di rumah sakit merupakan nilai bobot yang paling tinggi, setelah itu gedung dan fasilitas rujukan. Sedangkan untuk pelayanan dan kenyamanan merupakan kriteria yang paling rendah nilai bobot nya.

Tabel 2. Data Asumsi Rumah Sakit Rujukan

\begin{tabular}{clc}
\hline No. & Nama Rumah Sakit & Asumsi \\
\hline 1. & RSU Mitra Sejati & RS1 \\
2. & RS Adam Malik & RS 2 \\
3. & RS Pringadi & RS 3 \\
4. & RSU USU & RS 4 \\
5. & RS Siti Hajar & RS 5 \\
6. & RS Herna & RS 6 \\
7. & RS Mitra Medika & RS 7 \\
8. & RS Prof Boloni & RS 8 \\
9. & RS Mata SMEC & RS 9 \\
10. & RSU Marta Friska & RS 10 \\
\hline
\end{tabular}

Tabel 2 merupakan data asumsi Rumah sakit di kota Medan, yang akan dijadikan sebagai rumah sakit rujukan dari Puskesmas bagi Pasien BPJS.

\section{HASII DAN PEMBAHASAN}

Setelah melakukan analisa dari sampel data yang di dapat, maka selanjutnya melakukan penilaian yang diberikan oleh Dokter kepada masing-masing pasien. Adapun penilaian tersebut sebagai berikut:

Tabel 3. Data Calon Rumah Sakit Terbaik

\begin{tabular}{ccccccc}
\hline \multirow{2}{*}{ No. } & \multirow{2}{*}{ Alternatif } & \multicolumn{5}{c}{ Nama Kriteria } \\
\cline { 3 - 6 } & & C1 & C2 & C3 & C4 & C5 \\
\hline 1. & RS 1 & 58 & 70 & 78 & 67 & 48 \\
2. & RS 2 & 80 & 80 & 78 & 70 & 66 \\
3. & RS 3 & 68 & 80 & 78 & 79 & 84 \\
\hline
\end{tabular}




\begin{tabular}{cllllll}
\hline \multirow{2}{*}{ No. } & \multirow{2}{*}{ Alternatif } & \multicolumn{5}{c}{ Nama Kriteria } \\
\cline { 3 - 6 } & & C1 & C2 & C3 & C4 & C5 \\
\hline 4 & RS 4 & 80 & 58 & 78 & 40 & 41 \\
5. & RS 5 & 59 & 57 & 78 & 63 & 61 \\
6. & RS 6 & 80 & 60 & 78 & 77 & 85 \\
7. & RS 7 & 70 & 75 & 78 & 40 & 78 \\
8. & RS 8 & 70 & 76 & 78 & 68 & 74 \\
9. & RS 9 & 81 & 80 & 78 & 40 & 51 \\
10. & RS 10 & 65 & 72 & 78 & 40 & 51 \\
\hline
\end{tabular}

Berdasarkan rumus pada persamaan (1), maka perhitungan dari WSM sebagai berikut :

- RS 1

$$
\begin{aligned}
& =(0.15 * 58)+(0.15 * 70)+(0.5 * 78)+(0.10 * 0.67)+(0.10 * 48) \\
& =8,7+10,5+39+6,9+4,8 \\
& =69,7
\end{aligned}
$$

- RS 2

$=(0.15 * 80)+(0.15 * 80)+(0.5 * 78)+(0.10 * 70)+(0.10 * 66)$

$=12+12+39+7+6,6$

$=76,6$

- RS 3

$=(0.15 * 68)+(0.15 * 80)+(0.5 * 78)+(0.10 * 79)+(0.10 * 84)$

$=10,2+12+39+7,9+8,4$

$=77,5$

- RS 4

$=(0.15 * 80)+(0.15 * 58)+(0.5 * 78)+(0.10 * 40)+(0.10 * 41)$

$=12+8,7+39+4+4,1$

$=67,8$

- RS 5

$=(0.15 * 59)+(0.15 * 57)+(0.5 * 78)+(0.10 * 63)+(0.10 * 61)$

$=8,85+8,55+39+6,3+6,1$

$=68,8$

- RS 6

$=(0.15 * 80)+(0.15 * 60)+(0.5 * 78)+(0.10 * 77)+(0.10 * 85)$

$=12+9+39+7,7+7,7$

$=75,1$

- $\quad$ RS 7

$=(0.15 * 70)+(0.15 * 75)+(0.5 * 78)+(0.10 * 40)+(0.10 * 78)$

$=10,+11,25+39+4+7,8$

$=72,55$

- RS 8

$=(0.15 * 70)+(0.15 * 76)+(0.5 * 78)+(0.10 * 68)+(0.10 * 74)$

$=10,5+11,4+39+6,8+7,4$

$=75,1$ 


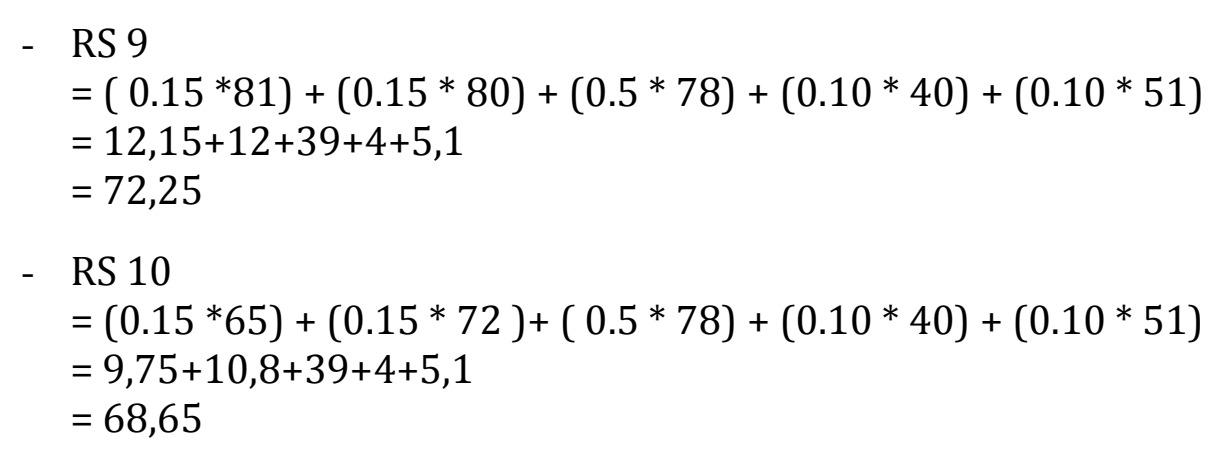

Tabel 4. Hasil Rangking Rumah Sakit Terbaik

\begin{tabular}{cccc}
\hline No. & Nama Alternatif & Hasil & Keterangan \\
\hline 1. & RS3 & 77,5 & Rangking 1 \\
2. & RS2 & 76,6 & Rangking 2 \\
3. & RS6 & 75,4 & Rangking 3 \\
4. & RS8 & 75,1 & Rangking 4 \\
5. & RS7 & 72,55 & Rangking 5 \\
6. & RS9 & 72,25 & Rangking 6 \\
7. & RS1 & 69,7 & Rangking 7 \\
8. & RS10 & 68,65 & Rangking 8 \\
9. & RS5 & 68,8 & Rangking 9 \\
10. & RS4 & 67,8 & Rangking 10 \\
\hline
\end{tabular}

Pada tabel 4 dapat dilihat hasil perangkingan dari data Rumah Sakit. Dari perhitungan yang sudah dibahas sebelumnya diperoleh nilai tertinggi 0.3875 sehingga dapat diputuskan bahwa RS3 merupakan alternatif yang terbaik dari alternatif yang lain dan merupakan di urutan pertama dalam daftar rujukan Rumah Sakit bagi pasien BPJS. Sistem Pendukung Keputusan ini juga diimplementasikan kedalam sebuah program visual dengan menggunakan Microsoft Visual Studio 2010 dengan database Microsoft Access 2010. Program ini terdiri dari 5 Form utama, antara lain:

\subsection{Form Kriteria}

Berdasarkan gambar 2, Form kriteria digunakan untuk menginputkan nilai kriteria. Kriteria sudah ditentukan oleh sistem, berdasarkan hasil riset. Jadi, user hanya dapat menginputkan bobot untuk masing-masing kriteria.

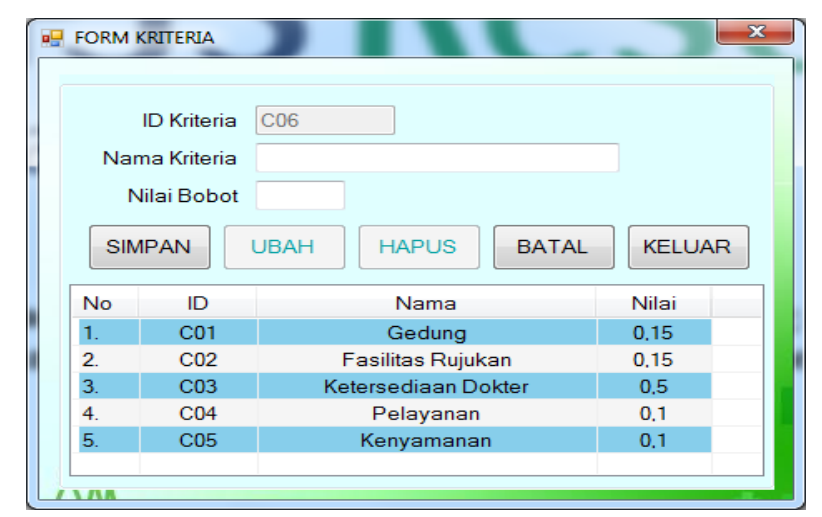

Gambar 2. Form Kriteria 


\subsection{Form Rumah Sakit}

Berdasarkan gambar 3, Form Rumah Sakit adalah form yang digunakan untuk menginputkan data rumah sakit.

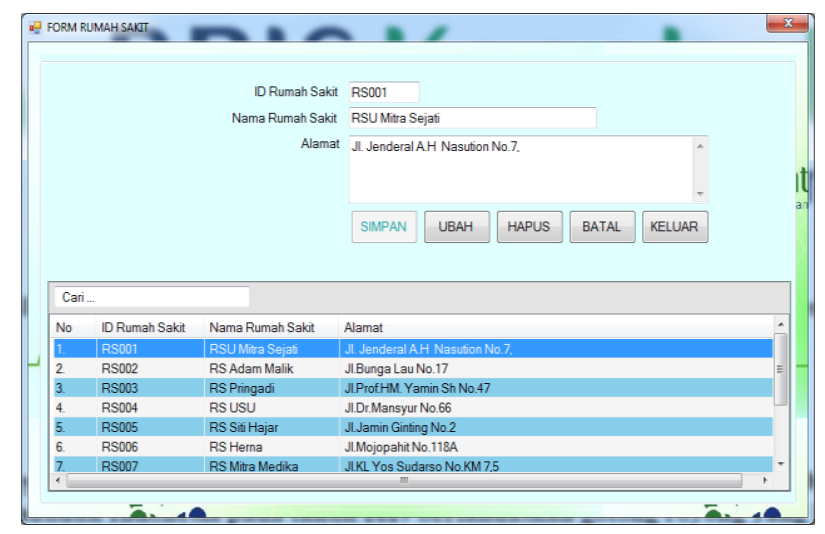

Gambar 3. Form Rumah Sakit

\subsection{Form Nilai Rumah Sakit}

Berdasarkan gambar 4, Form nilai Rumah Sakit adalah form yang digunakan untuk menginputkan data nilai rumah sakit.

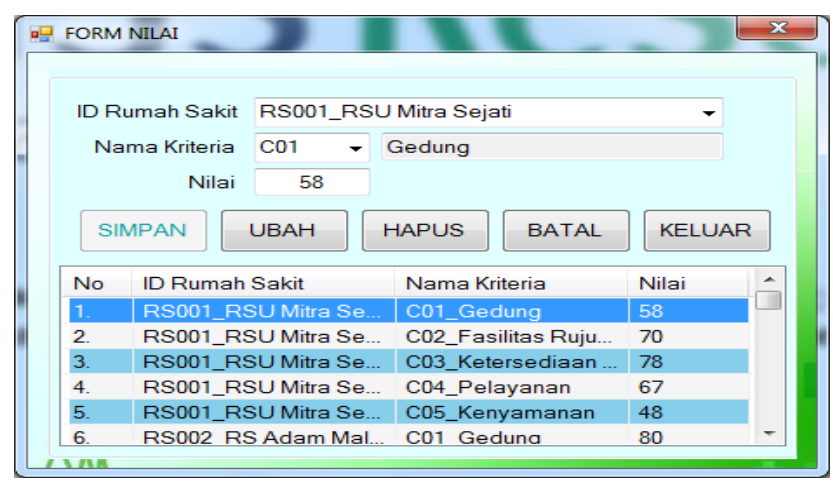

Gambar 4. Form Nilai Rumah Sakit

\subsection{Form Normalisasi dan Preferensi}

Berdasarkan gambar 5, Form normalisasi dan preferensi digunakan untuk memproses normalisasi data alternatif menjadi sesuai dengan range yang telah ditentukan, lalu menghitung nilai akhir menggunakan metode WSM. 


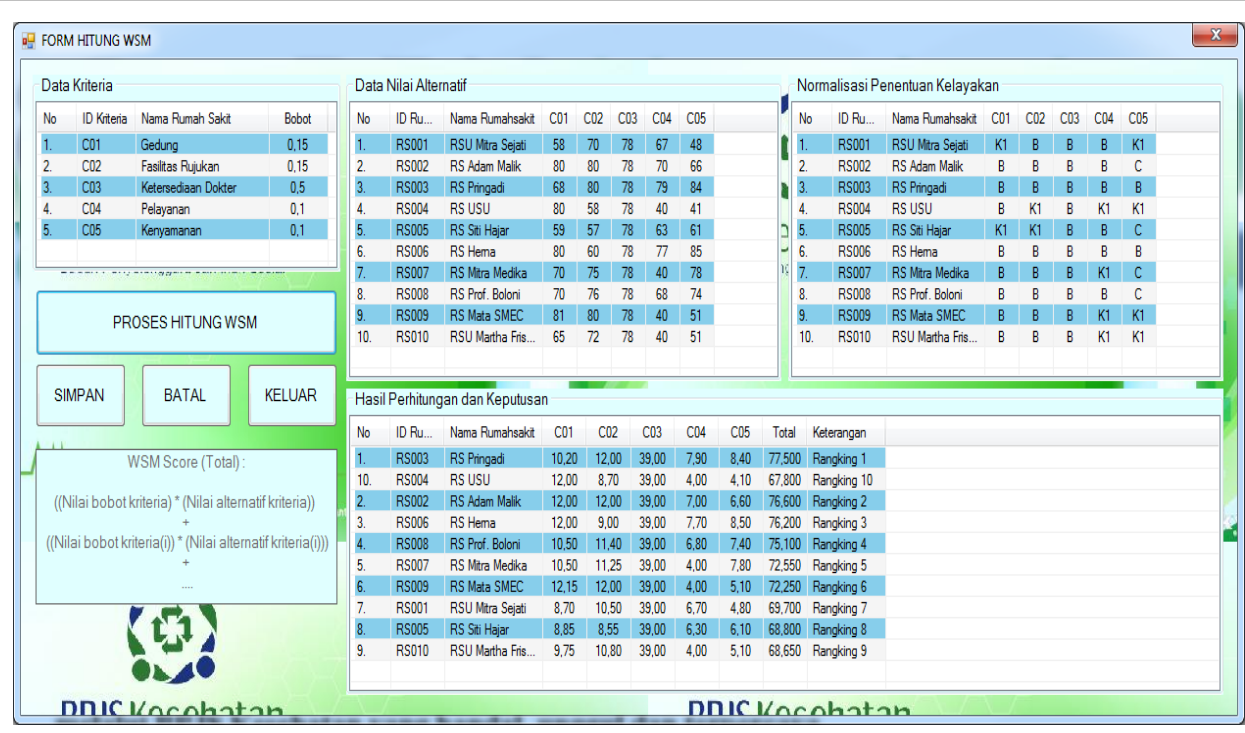

Gambar 5. Form Normalisasi dan Preferensi

\subsection{Form Laporan}

Berdasarkan Gambar 6, Form laporan digunakan untuk menampilkan laporan atau hasil perangkingan dari nilai-nilai alternatif rumah sakit yang akan menjadi rujukan bagi pasien BPJS.

\begin{tabular}{|c|c|c|c|c|c|}
\hline \multicolumn{6}{|c|}{ DAFTAR RUJUKAN RUMAH SAKIT BAGI PASIEN BPIS } \\
\hline & & & \multicolumn{3}{|c|}{ Medan, 21 Juli 2018} \\
\hline & ID RmhSakit & Nama Rumah Sakit & Alamat Rumah Sakit & Nilai RS & Keterangan \\
\hline 1 & RS001 & RSU Mitra Sejati & 71. Jenderal A.H Nasution No.7, & 69,700 & Rangking 7 \\
\hline 2 & RS002 & RS Adam Malik & Jl.Bunga Lau No.17 & 76,600 & Rangking 2 \\
\hline 3 & RS003 & RS Pringadi & J1.Prof.HM. Yamin Sh No.47 & 77,500 & Rangking 1 \\
\hline 4 & RS004 & RS USU & J1.Dr.Mansyur No.66 & 67,800 & Rangking 10 \\
\hline 5 & RS005 & \begin{tabular}{|l} 
RS Siti Hajar \\
\end{tabular} & Jl.Jamin Ginting No.2 & 68,800 & Rangking 8 \\
\hline 6 & RS006 & RS Hema & Jl.Mojopahit No.118A & 76,200 & Rangking 3 \\
\hline 7 & RS007 & RS Mitra Medika & Jl.KL Yos Sudarso No.KM 7,5 & 72,550 & Rangking 5 \\
\hline 8 & RS008 & \begin{tabular}{|l|} 
RS Prof. Boloni \\
\end{tabular} & J1. Wolter Mongonsidi No.11 & 75,100 & Rangking 4 \\
\hline 9 & RS009 & RS Mata SMEC & Jl. Iskandar Muda No. 278-280 & 72,250 & Rangking 6 \\
\hline 10 & RS010 & RSU Martha Friska & J1. KL Yos Sudarso KM.6 No.91 & 68,650 & Rangking 9 \\
\hline
\end{tabular}

\section{Gambar 6. Form Laporan}

\section{SIMPULAN}

Berdasarkan permasalah yang diteliti dan pengujian yang telah dilakukan maka dapat diambil kesimpulan terhadap analisa metode WSM dalam menentukan rujukan rumah sakit terbaik bagi pasien pengguna BPJS sebagai berikut :

a. Dalam merancang Sistem Pendukung Keputusan untuk Menentukan rujukan rumah sakit terbaik bagi pasien pengguna BPJS yaitu dengan memproses nilai/bobot setiap alternatif yang terlah diisi oleh user kemudian akan 
menampilkan nilai akhir setiap alternative (output) yang akan membantu dalam pengambilan keputusan.

b. Sistem Pendukung Keputusan dalam menentukan rujukan rumah sakit terbaik bagi pasien pengguna BPJS yang dirancang ini dapat membantu mempermudah dan mempercepat para admin dalam penyajian informasi kepada pimpinan perusahaan.

c. Dengan aplikasi yang dirancang pada aplikasi Sistem Pendukung Keputusan Untuk Menentukan Rujukan Rumah Sakit Terbaik Bagi Pasien Pengguna BPJS dapat mempermudah mengetahui proses pengolahan data rujukan rumah sakit terbaik bagi pasien pengguna BPJS melalui sistem komputerisasi.

\section{DAFTAR PUSTAKA}

[1] I. R. Wulansari, A. Suprayogi, and A. L. Nugraha, "Pembuatan Aplikasi Sebaran Lokasi Fasilitas Kesehatan Penerima Bpjs Kesehatan Di Kota Semarang Berbasis Android," J. Geod. Undip, vol. 4, no. 4, pp. 240-247, 2015.

[2] V. et. a. T. Handayani, "Segmentasi Geografi dan Perilaku Berpengaruh terhadap Keputusan Memilih Layanan Rawat Inap di Rumah Sakit," J. Kedokt. Brawijaya, vol. 29, no. 3, pp. 255260, 2017.

[3] Y. Yuniar and R. S. Handayani, "Kepuasan Pasien Peserta Program Jaminan Kesehatan Nasional terhadap Pelayanan Kefarmasian di Apotek," J. Kefarmasian Indones., vol. 6, no. 1, pp. 39-48, 2016.

[4] A. Wanto, "Analisis Penerapan Fuzzy Inference System (FIS) Dengan Metode Mamdani Pada Sistem Prediksi Mahasiswa Non Aktif (Studi Kasus : AMIK Tunas Bangsa Pematangsiantar),” in Seminar Nasional Inovasi Dan Teknologi Informasi (SNITI) 3, 2016, vol. 3, pp. 393-400.

[5] Agus Perdana Windarto, "Implementasi metode topsis dan saw dalam memberikan reward pelanggan,” Kumpul. J. Ilmu Komput., vol. 4, no. 1, pp. 88-101, 2017.

[6] A. P. Windarto, "Penilaian Prestasi Kerja Karyawan PTPN III Pematangsiantar Dengan Metode Simple Additive Weighting (SAW)," J. Ris. Sist. Inf. Dan Tek. Inform., vol. 2, no. ISSN 2527-5771, pp. 84-95, 2017.

[7] A. P. Windarto, "Penerapan Data Mining Pada Ekspor Buah-Buahan Menurut Negara Tujuan Menggunakan K-Means Clustering," Techno.COM, vol. 16, no. 4, pp. 348-357, 2017.

[8] T. Imandasari and A. P. Windarto, "Sistem Pendukung Keputusan dalam Merekomendasikan Unit Terbaik di PDAM Tirta Lihou Menggunakan Metode Promethee,” J. Teknol. dan Sist. Komput., vol. 5, no. 4, p. 159, 2017.

[9] A. Wanto and E. Kurniawan, "Seleksi Penerimaan Asisten Laboratorium Menggunakan Algoritma AHP Pada AMIK-STIKOM Tunas Bangsa Pematangsiantar," J. Inform. dan Komput., vol. 3, no. 1, pp. 11-18, 2018.

[10] M. Widyasuti, A. Wanto, D. Hartama, and E. Purwanto, "Rekomendasi Penjualan Aksesoris Handphone Menggunakan Metode Analitycal Hierarchy Process (AHP)," Konf. Nas. Teknol. Inf. dan Komput., vol. 1, no. 1, pp. 27-32, 2017.

[11] A. Wanto and H. Damanik, "Analisis Penerapan Sistem Pendukung Keputusan Terhadap Seleksi Penerima Beasiswa BBM (Bantuan Belajar Mahasiswa) Pada Perguruan Tinggi Menggunakan Metode Simple Additive Weighting (SAW) (Studi Kasus : AMIK Tunas Bangsa Pematangsiantar)," in Seminar Nasional Rekayasa (SNTR) II, 2015, no. 2, pp. 323-333.

[12] A. Muhith, S. Siyoto, and R. E. Rahmah, "Hubungan Karakteristik Pasien Pengguna Kartu BPJS Dengan Persepsi Tentang Kualitas Pelayanan Kesehatan Di Puskesmas Deket Kabupaten Lamongan," J. Medica Majapahit, vol. 9, no. 1, pp. 72-83, 2017.

[13] H. Febriawati, W. Angraini, S. Ekowati, and D. Astuti, "Analisis Manajemen Bencana Gempa di Rumah Sakit Umum Daerah Dr. M. Yunus Kota Bengkulu," J. Ilmu Kesehat. Masy., vol. 8, no. 1, pp. 29-34, 2017.

[14] T. Imandasari, A. Wanto, and A. P. Windarto, "Analisis Pengambilan Keputusan Dalam Menentukan Mahasiswa PKL Menggunakan Metode PROMETHEE,” J. Ris. Komput., vol. 5, no. 3, pp. 234-239, 2018.

[15] P. P. P. A. N. W. F. I. R. H. Zer and A. P. Windarto, "Analisis Pemilihan Rekomendasi Produk 
Terbaik Prudential Berdasarkan Jenis Asuransi Jiwa Berjangka Untuk Kecelakaan Menggunakan Metode Analytic Hierarchy Process ( Ahp )," CESS (Journal Comput. Eng. Syst. Sci., vol. 3, no. 1, pp. 78-82, 2018.

[16] A. Putrama and A. P. Windarto, "Analisis dalam menentukan produk bri syariah terbaik berdasarkan dana pihak ketiga menggunakan ahp," CESS (Journal Comput. Eng. Syst. Sci., vol. 3, no. 1, pp. 60-64, 2018.

[17] S. Sundari, A. Wanto, Saifullah, and I. Gunawan, "Sistem Pendukung Keputusan Dengan Menggunakan Metode Electre Dalam Merekomendasikan Dosen Berprestasi Bidang Ilmu Komputer (Study Kasus di AMIK \& STIKOM Tunas Bangsa)," in Seminar Nasional Multi Disiplin Ilmu, 2017, pp. 1-6.

[18] Mesran, Suginam, S. D. Nasution, and A. P. U. Siahaan, "Penerapan Weighted Sum Model (WSM) Dalam Penentuan Peserta Jaminan Kesehatan Masyarakat," J. Ris. Sist. Inf. dan Tek. Inform., vol. 2, no. 1, pp. 40-47, 2017.

[19] S. Solikhun, "Perbandingan Metode Weighted Product Dan Weighted Sum Model Dalam Pemilihan Perguruan Swasta Terbaik Jurusan Komputer," Klik - Kumpul. J. Ilmu Komput., vol. 4, no. 1, pp. 70-87, 2017. 